\title{
Simultaneous Multifunctional Sorption of PFOS and Cr(VI) on Activated Carbon Prepared by One-Step Microwave Activation
}

\author{
Zhibao Zhu • Qin Zhou • Meiyi Zhang • Guangzhi He • \\ Gang Pan • Yuan Zhao
}

Received: 1 April 2015 / Accepted: 14 June 2015 / Published online: 14 July 2015

(C) Springer International Publishing Switzerland 2015

\begin{abstract}
Multifunctional sorbents, activated carbons (AC), were prepared by one-step microwave activation utilizing peanut shells and sunflower seed husks. The influence of the original particle size of raw materials on the yield and specific surface area of AC was studied, which reached $33.5 \%$ and $1133.27 \mathrm{~m}^{2} / \mathrm{g}$, respectively. The repetitive and competitive uptakes of perfluorooctane sulfonate (PFOS) and chromium were applied to investigate the sorption properties of AC. The sorption mechanisms were demonstrated using sulfur Kedge X-ray absorption near edge structure analysis (XANES). In the repetitive experiment, $\mathrm{AC}$ made from peanut shells $\left(\mathrm{AC}_{\mathrm{P} 05}\right)$ still retained $70 \%$ removal efficiency of PFOS after the fourth sorption because sorbed PFOS might form a new organic phase that supplied effective sites for the hydrophobic partition of PFOS. However, the removal efficiency of $\mathrm{Cr}(\mathrm{VI})$ decreased dramatically from 60 to $11 \%$ after the fourth uptake because electrostatic attraction was its only removal pathway. In the binary solutes system, $\mathrm{AC}_{\mathrm{P} 05}$ possessed perfect sorption performance for both PFOS and $\mathrm{Cr}(\mathrm{VI})$, which were 885 and $192 \mathrm{mg} / \mathrm{g}$, respectively. In the multivariate solutes system, the XANES spectra indicated that the thiol functional group existed in the resulting
\end{abstract}

\section{Z. Zhu $\cdot$ Y. Zhao}

School of Environmental \& Safety Engineering, Changzhou University, Changzhou 213164, China

Z. Zhu $\cdot$ Q. Zhou $(\bowtie) \cdot$ M. Zhang $\cdot$ G. He $\cdot$ G. Pan $(\bowtie)$

Research Center for Eco-Environmental Sciences, Chinese

Academy of Sciences, Beijing 100085, China

e-mail: qinzhou@rcees.ac.cn

e-mail: gpan@rcees.ac.cn
$\mathrm{AC}$ and a metal chelate was formed between thiol and $\mathrm{Zn}^{2+} / \mathrm{Cu}^{2+}$. Hence, the presence of $\mathrm{Zn}^{2+} / \mathrm{Cu}^{2+}$ further promoted the removal of PFOS and $\mathrm{Cr}(\mathrm{VI})$ through the electrostatic attraction between the anions and positive metal chelate.

Keywords Activated carbon $\cdot \mathrm{Cr}(\mathrm{VI}) \cdot$ PFOS $\cdot$ Sorption mechanism $\cdot$ XANES

\section{Introduction}

Perfluorooctane sulfonate (PFOS, $\mathrm{C}_{8} \mathrm{~F}_{17} \mathrm{O}_{3}{ }^{-}$) has drawn considerable scientific and public concern due to its wide applications and ubiquitous contamination in various media (Ahrens et al. 2010; Giesy and Kannan 2001; Lam et al. 2014; Pan and You 2010; Zhang et al. 2011b). Although the 3M Company has phased out PFOS, the substance is still used in some specialized fields such as the firefighting and electroplating industry. In an electroplating plant, PFOS is usually utilized as an inhibitor of chromium (Cr) fog to reduce the atmospheric pollution of $\mathrm{Cr}$ during the electroplating process. Eventually the high concentration of PFOS mixed with coexisted $\mathrm{Cr}(\mathrm{VI}), \mathrm{Cu}$, and $\mathrm{Zn}$ is discharged into natural waterbodies via the effluent of wastewater from the electroplating plant (Wang and Xiao 1995). Various methods were developed to remove $\mathrm{Cr}(\mathrm{VI})$ (Yuan et al. 2009) and PFOS (Vecitis et al. 2009; Zhang et al. 2011a; Zhou et al. 2013a), respectively, because of the endocrine-disrupting effect of PFOS and the carcinogenic effect of $\mathrm{Cr}(\mathrm{VI})$. Sorption is effective in 
simultaneously removing PFOS and $\mathrm{Cr}(\mathrm{VI})$ from water (Zhou et al. 2013a). There is an urgent need to discover sorbents that are both economic and effective for simultaneous removal of PFOS and $\mathrm{Cr}(\mathrm{VI})$.

Activated carbon (AC) is a perfect sorbent for most contaminants from aqueous or gaseous environments due to the functionalized surface and high specific surface area. However, the higher cost of activated carbon is an important consideration because of its use of nonrenewable raw materials and conventional heating methods. Recently, cost cutting in producing $\mathrm{AC}$ has focused on utilizing raw materials/precursors from agricultural solid waste or by-product, including cotton stalk, rice husks, orange peel, and sunflower seed oil residue (Deng et al. 2009, 2010; Foo and Hameed 2011). In addition to the precursor or raw material, the heating method also affects the properties and cost of AC. For conventional heating, the temperature gradient proceeds from the surface to the interior of the particle within several hours, which results in a relatively larger energy loss and increases the expense. In contrast, microwave activation is a promising technique for preparing $\mathrm{AC}$ because of its short reaction time and low energy consumption. Microwave radiation is an internal and volumetric reaction, in which a high sintering temperature causes some released components to generate additional pores, which consequently supplies effective sorption sites and space (Hesas et al. 2013).

Peanuts and sunflower seeds are the main oil crops in China that yield more than 4500 and 200 kilotons per annum of peanut shells (PNS) and sunflower seed husks (SFSH), respectively. Most of these products are burnt as wastes, which causes environmental pollution and the loss of a precious resource. Therefore, preparing activated carbon using the shells of peanuts and sunflower seeds not only reduces the cost of waste disposal but also addresses the environmental problem. In this study, the influence of the particle size of raw materials (i.e., PNS and SFSH) on the yield and physic-chemistry of the resulting activated carbon by one-step microwave technology was evaluated. With a view to treat the wastewater from the electroplating process, the single sorption, repetitive and competitive uptakes of PFOS and $\mathrm{Cr}(\mathrm{VI})$ from aqueous solution were studied to estimate the removal performance of AC. The sorption mechanisms of PFOS and $\mathrm{Cr}(\mathrm{VI})$ on activated carbon were interpreted based on their uptake behavior and sulfur K-edge X-ray absorption near edge structure analysis (XANES) spectra analyses.

\section{Materials and Methods}

\subsection{Materials}

The peanut shell (PNS) and sunflower seed husks (SFSH) were collected from a local food bazaar. The perfluorooctane sulfonate (PFOS, $98 \%$ ) was purchased from Fluka (Milwaukee, WI, USA). The chemical reagents $\mathrm{K}_{2} \mathrm{Cr}_{2} \mathrm{O}_{7}, \mathrm{ZnCl}_{2}$, and $\mathrm{CuCl}_{2}$ were obtained from China National Medicines Corporation Ltd. The HPLCgrade methanol was obtained from Fisher Scientific Chemical (USA). All of the other reagents used in the experiment were analytical grade.

\subsection{Preparation of Activated Carbon}

The PNS and SFSH were crushed using a grinder to obtain two particle sizes: 5 and $0.5 \mathrm{~mm}$. The particles were washed with deionized water to remove any impurities. Then, the cracked shells were dried at $80^{\circ} \mathrm{C}$ for $24 \mathrm{~h}$. The activation process was modified based on the previous studies (Alslaibi et al. 2013; Hesas et al. 2013). Twenty grams of dried shells was immersed in $70 \mathrm{~mL}$ of $\mathrm{ZnCl}_{2}(50 \% \mathrm{wt})$ for $15 \mathrm{~h}$ in a quartz crucible at room temperature. The quartz crucible was placed inside the microwave oven (Galanz WD750S) at a radiation power of $750 \mathrm{~W}$ for $10 \mathrm{~min}$. Then, the samples were cooled to room temperature. A volume of $250 \mathrm{~mL}$ of dilute hydrochloric acid $\left(V_{\mathrm{HCl}}: V_{\mathrm{H}_{2} \mathrm{O}}=1: 9\right)$ was added to the quartz crucible and allowed to boil for $30 \mathrm{~min}$ to remove the ash content. The products were then washed with deionized water to neutralize the $\mathrm{pH}$ and remove chlorine ions. The moist materials were dried at $80{ }^{\circ} \mathrm{C}$ for $24 \mathrm{~h}$ and then ground to obtain 200 mesh activated carbon. The resulting activated carbon products were marked as $\mathrm{AC}_{\mathrm{P} 5}, \mathrm{AC}_{\mathrm{P} 05}, \mathrm{AC}_{\mathrm{S} 5}$, and $\mathrm{AC}_{\mathrm{S} 05}$. The subscripts "P" and "S" represent peanut shell and sunflower seed husks, respectively. The numbers " 5 " and " 05 " indicate the 5 and $0.5 \mathrm{~mm}$ of particles, respectively. The dry activated carbon was weighed to calculate the product yield according to Eq. (1):

yield $(\%)=W_{\mathrm{R}} / W_{0} \times 100 \%$

where $W_{\mathrm{R}}$ and $W_{0}$ are the weights $(\mathrm{g})$ of the activated carbon and raw material, respectively. 


\subsection{Characterization of Activated Carbon}

The specific surface area (Brunauer-Emmett-Teller, $\mathrm{BET}$ ), pore size distribution, and pore volume were determined according to the BET equation and the $\mathrm{BJH}$ method from the adsorption-desorption isotherm of $\mathrm{N}_{2}$ at $77 \mathrm{~K}$ using ASAP $2020 \mathrm{HD} 88$ (Micromeritics, USA). The morphology of the activated carbon was observed using field emission scanning electron microscopy (FE-SEM, HITACHI SU8020). The Fourier transform infrared (FTIR) spectrum of the samples was obtained on an FTIR spectrophotometer (NEXUS 670, Nicolet, USA) by attenuated total reflectance (ATR) within the $400-4000 \mathrm{~cm}^{-1}$ range. The resolution of FTIR spectroscopy was $2.0 \mathrm{~cm}^{-1}$. The zeta potential was measured as described in a previous report (Zhou et al. 2010) with a ZETASIZER 2000 instrument (Malvern, USA). Sulfur K-edge XANES spectra analyses were conducted at the Canadian Light Source (CLS) on the Soft X-ray Micro-characterization Beamline (SXRMB) and the Beijing Synchrotron Radiation Facility (BSRF) on the 4B7A-Mid-energy Spectroscopy. The process was manipulated as follows: Air-dried samples were placed on a piece of doublesided carbon adhesive tape that was then transferred into the ultra-high-vacuum (UHV) chamber. In total, scans were run from 2430 to $2520 \mathrm{eV}$. To obtain high resolution in the pre-edge and edge region, a step size of $0.2 \mathrm{eV}$ was used from 2430 to $2464 \mathrm{eV}$ and a step size of $0.15 \mathrm{eV}$ was used from 2466 to $2485 \mathrm{eV}$. In the other regions, a step size of $1.0 \mathrm{eV}$ was used. A pre-edge background was removed from all spectra by fitting a straight line to the pre-edge region and subtracting this line from the entire spectrum.

\subsection{Sorption Experiments}

The sorption experiments included three systems: PFOS or $\mathrm{K}_{2} \mathrm{Cr}_{2} \mathrm{O}_{7}$ single solute, binary solute (PFOS and $\mathrm{K}_{2} \mathrm{Cr}_{2} \mathrm{O}_{7}$ ), and multivariate solute (PFOS, $\mathrm{K}_{2} \mathrm{Cr}_{2} \mathrm{O}_{7}$, $\mathrm{ZnCl}_{2}$, and $\mathrm{CuCl}_{2}$ ). Ten milligrams (10 $\mathrm{mg}$ ) of activated carbon was added to the polypropylene (PP) centrifuge tubes containing $25 \mathrm{~mL}$ of different initial concentrations of the $\mathrm{K}_{2} \mathrm{Cr}_{2} \mathrm{O}_{7}$ and/or PFOS solutions and $0.1 \mathrm{M}$ $\mathrm{NaH}_{2} \mathrm{PO}_{4}$ as a buffer solution. In the repetitive experiment, the initial concentration of PFOS or $\mathrm{Cr}(\mathrm{VI})$ was 400 or $159 \mathrm{mg} / \mathrm{L}$, respectively. After the first sorption equilibrium, the mixture was centrifuged at $3000 \mathrm{rpm}$ for $10 \mathrm{~min}$ and the supernatant was collected for determination of PFOS or $\mathrm{Cr}(\mathrm{VI})$. Then, another $25 \mathrm{~mL}$ of PFOS or $\mathrm{K}_{2} \mathrm{Cr}_{2} \mathrm{O}_{7}$ solution and $0.1 \mathrm{M}$ $\mathrm{NaH}_{2} \mathrm{PO}_{4}$ buffer solution were added into the PP tubes containing the remnant moist sorbent. After the second sorption equilibrium, the third and fourth operations were the same as the first one. It was noted that the sorbent was not regenerated in these repetitive sorption experiments.

In the competitive experiment, additional $\mathrm{CuCl}_{2}$ and $\mathrm{ZnCl}_{2}$ solutions with an initial concentration of $100 \mathrm{mg} / \mathrm{L}$ were added in the sorption system. It was noted that the concentrations of $\mathrm{K}_{2} \mathrm{Cr}_{2} \mathrm{O}_{7}, \mathrm{ZnCl}_{2}$, and $\mathrm{CuCl}_{2}$ were relevant to the wastewater from the electroplating plant. The $\mathrm{pH}$ values of all experiments were adjusted to 3.0 because the actual $\mathrm{pH}$ of the chromium-containing electroplating wastewater was close to this value (Lin et al. 2009; Tang et al. 2006). The increased volume of alkali/acid was negligible. On the basis of our preliminary experiment, the PP tubes were shaken at $150 \mathrm{rpm}$ for $120 \mathrm{~h}$ at room temperature to ensure equilibration. All of the sorption experiments were conducted in duplicate, and the average values were used in our analysis.

\subsection{Cr(VI) and PFOS Determination}

The concentration of PFOS was determined by ultraperformance liquid chromatography-tandem mass spectrometry (UPLC-MS/MS), the details of which can be found in our previous study (Zhou et al. 2013b). An inductively coupled plasma optical emission spectrometry (ICP-OES, IRIS Intrepid II XSP, USA) was used to determine the concentration of chromium (Zhou et al. 2013a). The uptake amount $\left(q_{\mathrm{e}}\right)$ of $\mathrm{Cr}$ or PFOS was calculated with Eq. (2):

$q_{\mathrm{e}}=\mathscr{G}\left(C_{0}-C_{\mathrm{e}}\right) \times V_{0} / M_{\mathrm{s}}$

where $C_{0}(\mathrm{mg} / \mathrm{L})$ is the initial concentration of PFOS or $\mathrm{Cr}(\mathrm{VI}), C_{\mathrm{e}}(\mathrm{mg} / \mathrm{L})$ is the equilibrium concentration of PFOS or Cr(VI), $V_{0}$ is the initial volume, and $M_{\mathrm{s}}$ is the mass $(\mathrm{g})$ of the sorbent.

\section{Results and Discussion}

\subsection{Effect of Raw Material and Original Particle Size}

There were no obvious influences of the raw material on the production yields of activated carbon, which ranged 
Table 1 Yield and structural parameters of four types of activated carbons

\begin{tabular}{lllll}
\hline Samples & $\mathrm{AC}_{\mathrm{S} 5}$ & $\mathrm{AC}_{\mathrm{S} 05}$ & $\mathrm{AC}_{\mathrm{P} 5}$ & $\mathrm{AC}_{\mathrm{P} 05}$ \\
\hline Yield $(\%)$ & 33.5 & 32.8 & 33.3 & 31.14 \\
BET $\left(\mathrm{m}^{2} / \mathrm{g}\right)$ & 3.12 & 700.34 & 744.75 & 1133.27 \\
Average pore size $(\mathrm{nm})$ & 37.0 & 3.3 & 3.5 & 3.7 \\
Pore volume $\left(\mathrm{m}^{3} / \mathrm{g}\right)$ & 0.03 & 0.54 & 0.54 & 0.93 \\
\hline
\end{tabular}

from 31.14 to $33.5 \%$ (Table 1). The yield of AC by microwave activation was lower in comparison with that achieved by the traditional thermal method (Huang et al. 2011) because the samples reached a higher temperature rapidly in minutes and the aggressive activation caused by the microwave radiation was intense. The volatiles and tar were released very quickly from the reaction system, which resulted in mass loss of the raw materials and reduced the production yield (Huang et al. 2011).

The structures of the AC derived from the different raw materials were different. The microwave activation failed to improve the specific surface area and pore volume of $\mathrm{AC}_{\mathrm{S} 5}$, which were $3.12 \mathrm{~m}^{2} / \mathrm{g}$ and $0.03 \mathrm{~m}^{3} / \mathrm{g}$, respectively (Table 1). Additionally, there were no abundant macro- or micro-pores in the bulk (Fig. 1a). When the original particle size of SFSH decreased from 5 to $0.5 \mathrm{~mm}$, the BET surface area of the resulting $\mathrm{AC}$ increased dramatically from 3.12 to $700.34 \mathrm{~m}^{2} / \mathrm{g}$. A smaller particle size of the precursor resulted in a more thorough activation with $\mathrm{ZnCl}_{2}$ because a relatively more surface area of the precursor was exposed to the $\mathrm{ZnCl}_{2}$ solution. For the raw material of PNS, the resulting $\mathrm{AC}_{\mathrm{P} 5}$ and $\mathrm{AC}_{\mathrm{P} 05}$ possessed much larger BET surface areas, which were 744.75 and $1133.27 \mathrm{~m}^{2} / \mathrm{g}$, respectively. The reticulated structures and abundant pores were observed from the morphology of $\mathrm{AC}_{\mathrm{P} 5}$ and $\mathrm{AC}_{\mathrm{P} 05}$ (Fig. 1c, d). The original structure of the raw material might be a factor that affected the final morphology of the AC. Clearly, the smooth surface of SFSH results in the bulk structure of $\mathrm{AC}_{\mathrm{S} 5}$ and $\mathrm{AC}_{\mathrm{S} 05}$. However, the fibrous texture of PNS is contributed by the reticulated structures and abundant pores of $\mathrm{AC}_{\mathrm{P} 05}$ and $\mathrm{AC}_{\mathrm{P} 5}$.

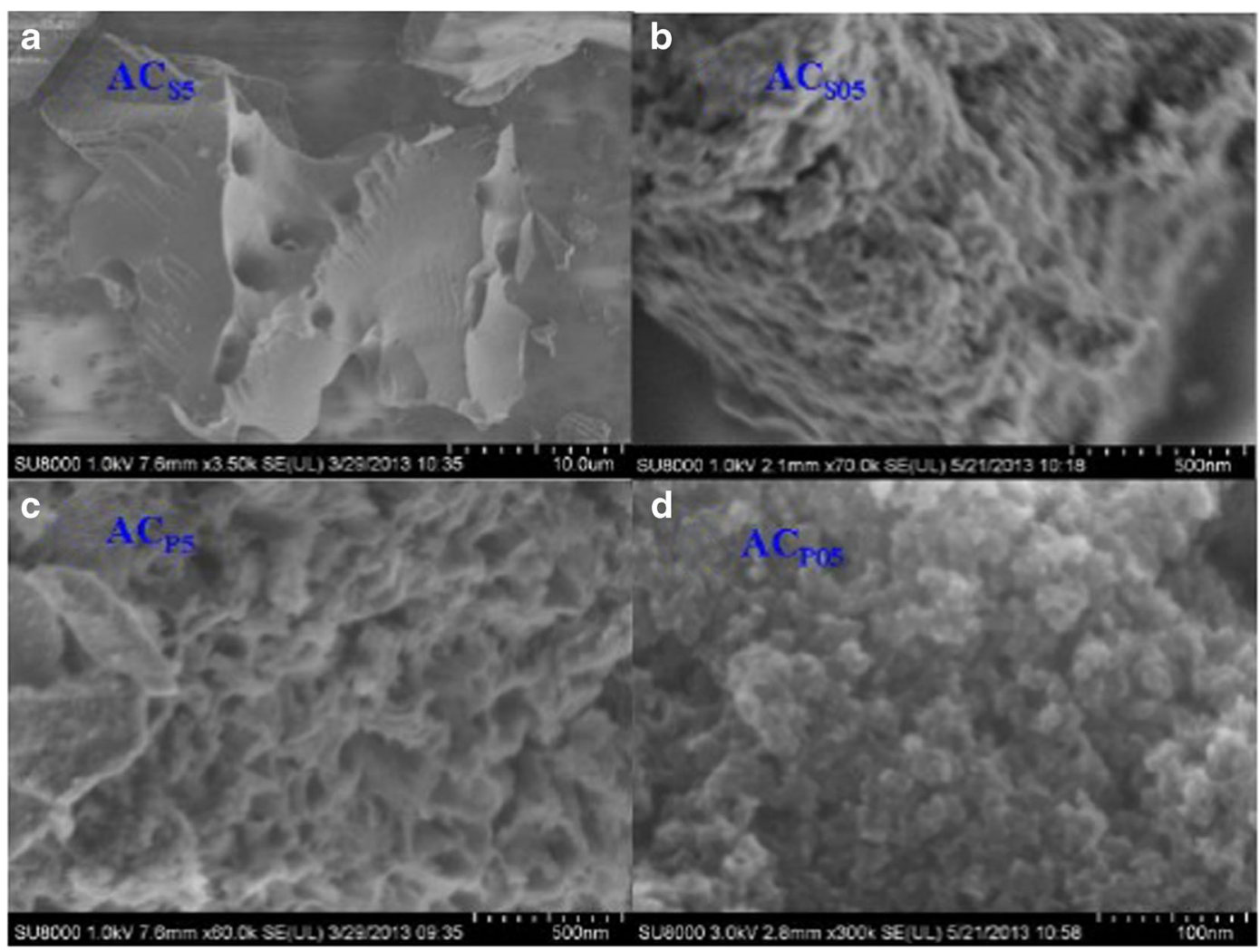

Fig. 1 SEM images of four types of resulting activated carbons 

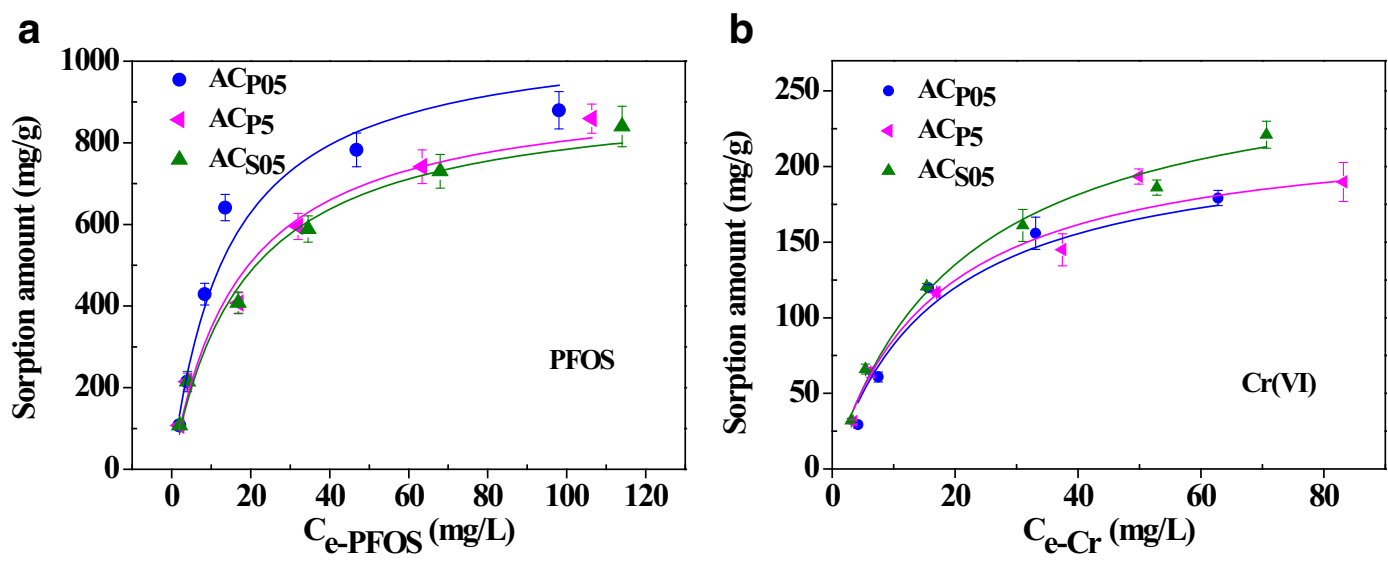

Fig. 2 Sorption isotherms of PFOS (a) and $\mathrm{Cr}(\mathrm{VI})(\mathbf{b})$ on three types of $\mathrm{AC}\left(C_{0-\mathrm{PFOS}} 50\right.$ to $400 \mathrm{mg} / \mathrm{L}$ and $C_{0-\mathrm{Cr}(\mathrm{VI})} 15.9$ to $\left.159 \mathrm{mg} / \mathrm{L}, \mathrm{pH} 3.0\right)$

\subsection{Sorption Isotherm and Mechanism}

Three types of $\mathrm{AC}$ with a larger $\mathrm{BET}$ area $\left(\mathrm{AC}_{\mathrm{S} 05}, \mathrm{AC}_{\mathrm{P} 5}\right.$, $\mathrm{AC}_{\mathrm{P} 05}$ ) were used as sorbents for PFOS and $\mathrm{Cr}(\mathrm{VI})$ (Fig. 2).

The sorption capacity of PFOS followed the order $\mathrm{AC}_{\mathrm{P} 05}>\mathrm{AC}_{\mathrm{P} 5} \approx \mathrm{AC}_{\mathrm{S} 05}$, whose maximum sorption amounts $\left(q_{\mathrm{m}}\right)$ totaled $1064.61,943.72$, and $926.79 \mathrm{mg} /$ g, respectively (Table 2). The $q_{\mathrm{m}}$ of PFOS on these resulting activated carbons were much higher than that on the commercial AC, in which $559 \mathrm{mg} / \mathrm{g}$ for powder $\mathrm{AC}$ and $199 \mathrm{mg} / \mathrm{g}$ for granular AC were measured (Yu et al. 2009). In this study, these AC had a positive potential at a $\mathrm{pH}$ of 3.0 (Fig. 3). We examined the infrared spectrum of $\mathrm{AC}$ and then found an intense absorption peak corresponding to the $\mathrm{C}=\mathrm{O}$ stretching frequency in the range from 1650 to $1850 \mathrm{~nm}^{-1}$ (Fig. 3). An oxygen-containing functional group such as pyrone, lactones, or ketone existed on the surface of AC (Boehm 2002), where the oxygen atom from the carbonyl would be protonated under acid conditions, resulting in their

Table 2 Equilibrium constants using the Langmuir model for PFOS and $\mathrm{Cr}(\mathrm{VI})$

\begin{tabular}{lllll}
\hline Sorbates & Sorbents & \multicolumn{4}{l}{ Langmuir constants } \\
\cline { 3 - 5 } & & $K_{L}(\mathrm{~L} / \mathrm{mg})$ & $q_{\mathrm{m}}(\mathrm{mg} / \mathrm{g})$ & $R^{2}$ \\
\hline PFOS & $\mathrm{AC}_{\mathrm{S} 05}$ & 0.055 & 926.79 & 0.985 \\
& $\mathrm{AC}_{\mathrm{P} 5}$ & 0.058 & 943.72 & 0.984 \\
& $\mathrm{AC}_{\mathrm{P} 05}$ & 0.07 & 1064.61 & 0.968 \\
$\mathrm{Cr}(\mathrm{VI})$ & $\mathrm{AC}_{\mathrm{S} 05}$ & 0.048 & 275.09 & 0.989 \\
& $\mathrm{AC}_{\mathrm{P} 5}$ & 0.060 & 229.85 & 0.974 \\
& $\mathrm{AC}_{\mathrm{P} 05}$ & 0.059 & 220.8 & 0.917 \\
\hline
\end{tabular}

positive potentials (Dicorcia et al. 1993). PFOS exists as an anion in this experiment because of its low $\mathrm{pK}_{\mathrm{a}}$ (Brooke et al. 2004). Hence, the electrostatic attraction between the anionic PFOS and the protonated functional groups of oxygen-containing moieties on the AC surface promoted the sorption of PFOS. The result was consistent with the previous reports (Yu et al. 2009).

Conversely, $\mathrm{AC}_{\mathrm{P} 5}$, which possessed the highest zeta potential at a $\mathrm{pH}$ of 3.0, was not the most efficient sorbent for PFOS. Therefore, other factors might affect the sorption capability of the $\mathrm{AC}$. $\mathrm{AC}_{\mathrm{P} 05}$ had the largest special surface area $\left(1133.27 \mathrm{~m}^{2} / \mathrm{g}\right)$, which was higher than that of $\mathrm{AC}_{\mathrm{P} 5}\left(744.75 \mathrm{~m}^{2} / \mathrm{g}\right)$ and $\mathrm{AC}_{\mathrm{S} 05}\left(700.34 \mathrm{~m}^{2} /\right.$ $\mathrm{g})$. The previous studies had proved that hydrophobic partition into $\mathrm{AC}$ was included during the sorption process because PFOS is a type of hydrophobic surfactant (Yu et al. 2009; Zhou et al. 2013b). Though $\mathrm{AC}_{\mathrm{P} 5}$ possessed the higher zeta potential, $\mathrm{AC}_{\mathrm{P} 05}$ had a larger BET area which could supply more hydrophobic sorption sites for PFOS. Hence, the sorption capacities of PFOS followed the decreasing order of $\mathrm{AC}_{\mathrm{P} 05}>\mathrm{AC}_{\mathrm{P} 5} \approx$ $\mathrm{AC}_{\mathrm{S} 05}$ due to both the hydrophobic partition and electrostatic attraction between PFOS and AC.

In contrast to the results obtained for PFOS, the sorption amounts of $\mathrm{Cr}(\mathrm{VI})$ on $\mathrm{AC}_{\mathrm{S} 05}, \mathrm{AC}_{\mathrm{P} 05}$, and $\mathrm{AC}_{\mathrm{P} 5}$ were similar, and the $q_{\mathrm{m}}$ values were 275.09 , 220.8 , and $229.85 \mathrm{mg} / \mathrm{g}$, respectively. The sorption capacity of $\mathrm{Cr}(\mathrm{VI})$ on $\mathrm{AC}$ was more than ten times than that on organo-clay ( $25 \mathrm{mg} / \mathrm{g}$ ) (Zhou et al. 2013a). Previously, Shi (1986) demonstrated that $\mathrm{Cr}(\mathrm{VI})$ exists as $\mathrm{HCrO}_{4}^{-}(89 \%)$ and $\mathrm{Cr}_{2} \mathrm{O}_{7}{ }^{2-}(11 \%)$ at a $\mathrm{pH}$ of 3.0 . Hence, the anionic $\mathrm{HCrO}_{4}^{-} / \mathrm{Cr}_{2} \mathrm{O}_{7}{ }^{2-}$ formed stable coordination compounds with the protonated oxygencontaining group via electrostatic attraction, which was 
Fig. 3 Zeta potential (a) and FTIR (b) of three types of AC a

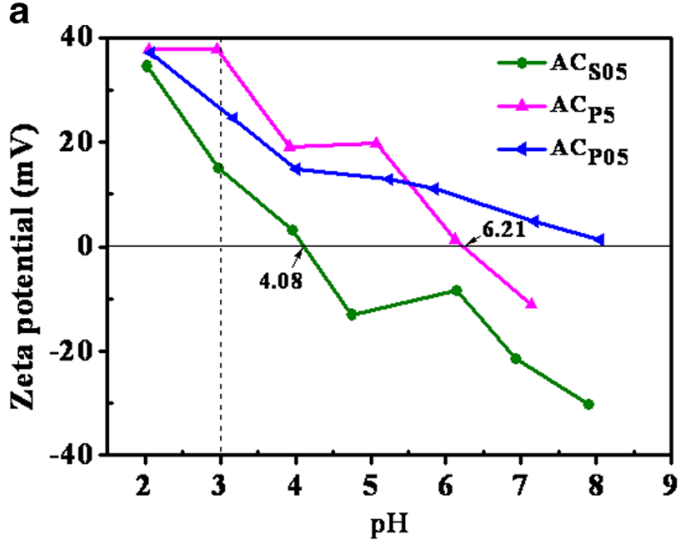

b

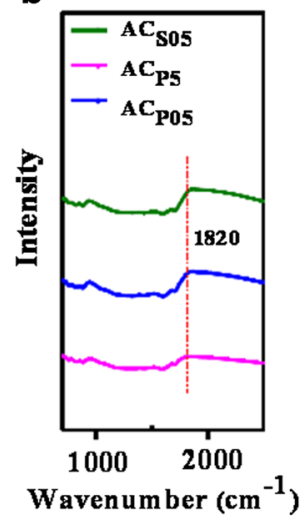

consistent with the interaction between $\mathrm{HCrO}_{4}{ }^{-}$and an amino group observed previously (Zhou et al. 2013a).

\subsection{Repetitive Sorption of PFOS and Cr(VI)}

To further study the performance of activated carbons, the repetitive sorption of PFOS or Cr(VI) was carried out (Fig. 4). The removal efficiency of PFOS reduced slightly approximately $10 \%$ after the third sorption and then increased slightly after the fourth sorption. Notably, the sorption ability and removal efficiency of PFOS on $\mathrm{AC}_{\mathrm{P} 05}$ still reached $786 \mathrm{mg} / \mathrm{g}$ and $70 \%$, respectively, after the fourth sorption. As mentioned above, both hydrophobic partition and electrostatic attraction involving PFOS were the driving forces during the sorption process. Although the electrostatic sorption sites were limited, the sorbed PFOS ions/molecules on the AC after the first sorption would form a new organic phase that supplied more effective sorption sites for the hydrophobic PFOS. Therefore, all the three types of AC retained better sorption efficiencies even after the fourth sorption.
Specifically, the removal efficiency of $\mathrm{Cr}(\mathrm{VI})$ decreased dramatically from 60 to $11 \%$ on $\mathrm{AC}_{\mathrm{P} 05}$, from 48 to $15 \%$ on $\mathrm{AC}_{\mathrm{P} 5}$, and from 56 to $21 \%$ on $\mathrm{AC}_{\mathrm{S} 05}$ after the repetitive fourth sorption. The distinguishing feature derived from the distinct sorption mechanisms of PFOS and $\mathrm{Cr}(\mathrm{VI})$. As mentioned above, the removal of $\mathrm{Cr}(\mathrm{VI})$ depended on the formation of stable coordination compounds via electrostatic attraction. When $\mathrm{Cr}(\mathrm{VI})$ was partially sorbed on the AC during the first sorption process, the effective electrostatic sites were occupied, which restricted the subsequent uptake of additional $\mathrm{Cr}(\mathrm{VI})$. Consequently, this resulted in a decreased removal efficiency of $\mathrm{Cr}(\mathrm{VI})$ after the repetitive sorption of $\mathrm{Cr}(\mathrm{VI})$.

\subsection{Competitive Sorption of PFOS and Cr(VI)}

The competitive sorption included binary solutes (i.e., PFOS and $\mathrm{K}_{2} \mathrm{Cr}_{2} \mathrm{O}_{7}$ ) and multivariate solutes systems (i.e., PFOS, $\mathrm{K}_{2} \mathrm{Cr}_{2} \mathrm{O}_{7}, \mathrm{ZnCl}_{2}$, and $\mathrm{CuCl}_{2}$ ) (Fig. 5).
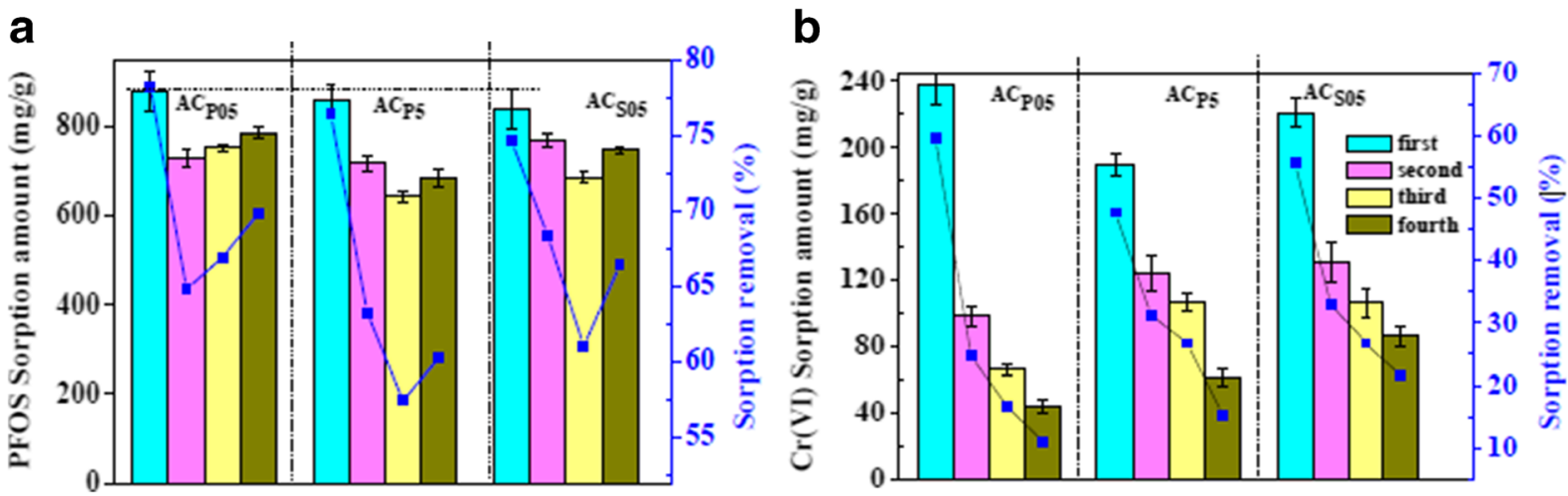

Fig. 4 Repetitious sorption of PFOS (a) and Cr(VI) (b) on three types of AC ( $C_{0 \text {-PFOS }} 400 \mathrm{mg} / \mathrm{L}$ and $C_{0-\mathrm{Cr}(\mathrm{VI})} 159 \mathrm{mg} / \mathrm{L}$, pH 3.0$)$ 

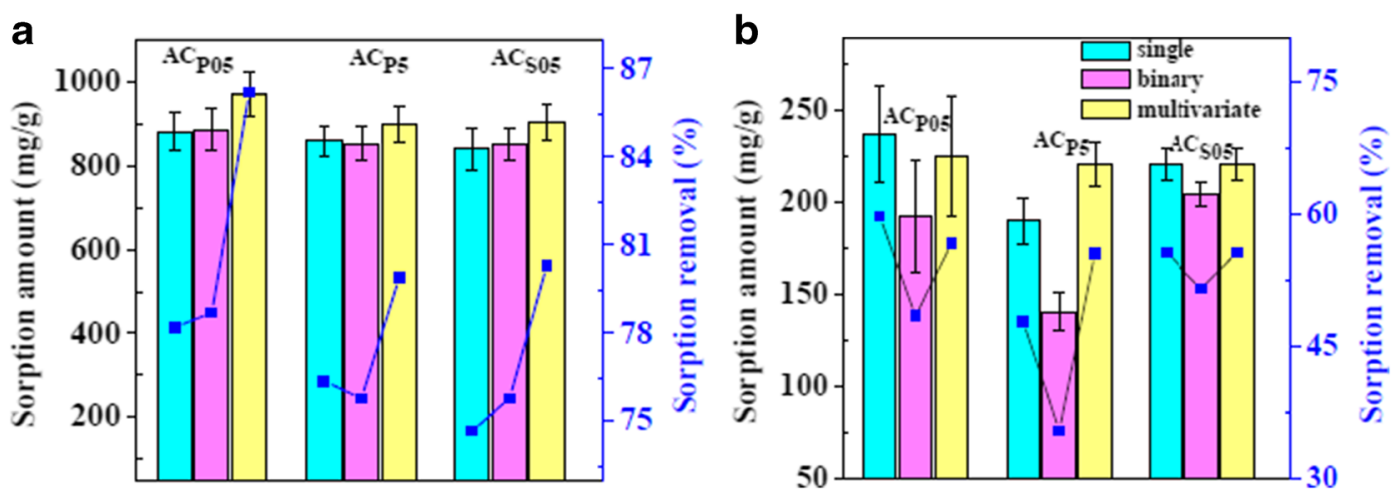

Fig. 5 Comparative sorption of PFOS (a) and $\mathrm{Cr}(\mathrm{VI})$ (b) on three types of $\mathrm{AC}$ in single solute, binary solutes, and multivariate solutes systems ( $C_{0-\mathrm{PFOS}} 400 \mathrm{mg} / \mathrm{L}, C_{0-\mathrm{Cr}(\mathrm{VI})} 159 \mathrm{mg} / \mathrm{L}, C_{0-\mathrm{Cu}} 37.5 \mathrm{mg} / \mathrm{L}$, and $\left.C_{0-\mathrm{Zn}} 47.7 \mathrm{mg} / \mathrm{L}, \mathrm{pH} 3.0\right)$

In the binary solutes system, there should be a competitive sorption between anionic $\mathrm{HCrO}_{4}{ }^{-} / \mathrm{Cr}_{2} \mathrm{O}_{7}{ }^{2-}$ and PFOS on the protonated AC surface. However, PFOS and $\mathrm{Cr}(\mathrm{VI})$ displayed different behaviors. The presence of anionic $\mathrm{HCrO}_{4}{ }^{-} / \mathrm{Cr}_{2} \mathrm{O}_{7}{ }^{2-}$ did not obviously affect the sorption capacity of PFOS on the AC because $\mathrm{Cr}(\mathrm{VI})$ only occupied the electrostatic sites, whereas PFOS could still be removed by hydrophobic partition (Fig. 5a). These results further indicated that the hydrophobic partition was included in the sorption process involving PFOS.

Figure $4 \mathrm{~b}$ shows that the presence of PFOS degraded the $\mathrm{Cr}(\mathrm{VI})$ sorption ability on these AC. The previous report indicated that the formation of a stable coordination via electrostatic attraction between the anionic $\mathrm{HCrO}_{4}{ }^{-} / \mathrm{Cr}_{2} \mathrm{O}_{7}{ }^{2-}$ and the protonated surface of sorbent was the only mechanism to remove the $\mathrm{Cr}(\mathrm{VI})$ (Zhou et al. 2013a). In the binary solutes system, the anionic PFOS occupied the partial electrostatic sorption sites, which resulted in a competition between $\mathrm{Cr}(\mathrm{VI})$ and
PFOS and a subsequent decrease in the removal of $\mathrm{Cr}(\mathrm{VI})$. The decrease of $\mathrm{Cr}(\mathrm{VI})$ removal efficiency on $\mathrm{AC}_{\mathrm{P} 05}$ in the repetitive sorption (from 60 to $11 \%$ ) and binary solutes system (from 60 to $48 \%$ ) indicated that the competition between $\mathrm{HCrO}_{4}^{-}$and $\mathrm{Cr}_{2} \mathrm{O}_{7}{ }^{2-}$ was stronger than that involving $\mathrm{HCrO}_{4}^{-}$and PFOS. That is, PFOS preferred hydrophobic partition rather than electrostatic attraction when competition between $\mathrm{PFOS}$ and $\mathrm{HCrO}_{4}{ }^{-}$ occurred. In general, $\mathrm{AC}_{\mathrm{P} 05}$ still possessed superior sorption capacity for both PFOS and $\mathrm{Cr}(\mathrm{VI})$ even in the competitive binary solutes system, which were $885 \mathrm{mg} /$ g (79 \% removal percentage) and $192 \mathrm{mg} / \mathrm{g}$ (48\% removal percentage), respectively. Surprisingly, the sorption capacity of both PFOS and $\mathrm{Cr}(\mathrm{VI})$ on the sorbents increased in the multivariate solutes system (Fig. 5). To interpret this phenomenon, sulfur K-edge XANES spectra for the samples containing $\mathrm{AC}_{\mathrm{P} 05}$, PFOS, $\mathrm{Cr}(\mathrm{VI})$, $\mathrm{Zn}^{2+}$, and $\mathrm{Cu}^{2+}$ were conducted (Fig. 6).

For $\mathrm{AC}_{\mathrm{P} 05}$, the intense peaks at energies of 2473.8 and $2482.2 \mathrm{eV}$ represented the thiol and sulfate on the basis of
Fig. 6 Normalized sulfur K-edge XANES spectra of models and samples
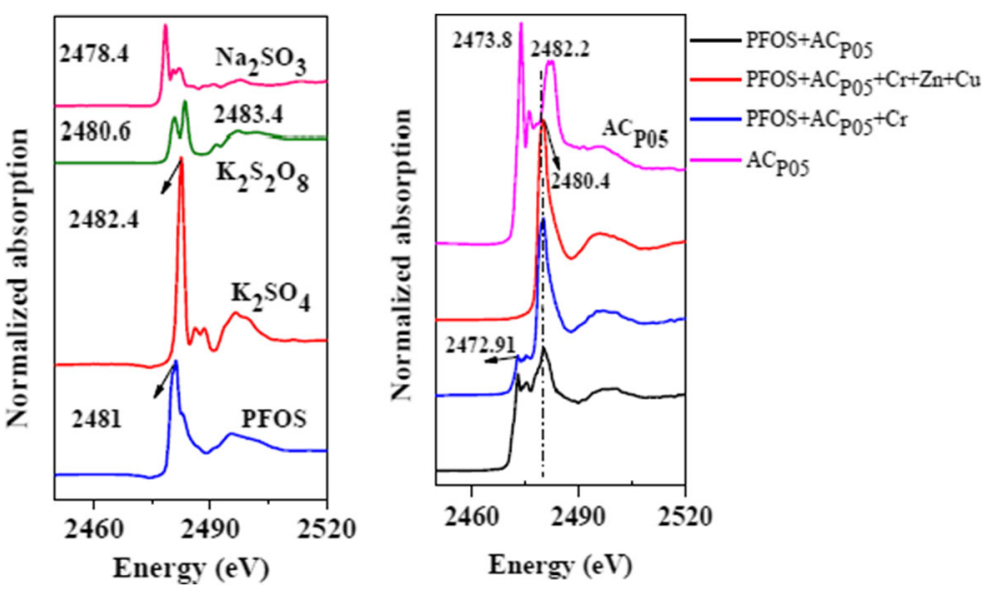
model samples and a previous report (Hashimoto and Yamaguchi 2013). The peak at $2481 \mathrm{eV}$ was attributed to the sulfonate moiety of the PFOS sample. For the $\mathrm{AC}_{\mathrm{P} 05}$ with sorbed PFOS in single, binary, and multivariate solutes systems, the characteristic absorption peak of PFOS (at $2481 \mathrm{eV}$ ) became stronger gradually and shifted from 2481 to $2480.4 \mathrm{eV}$. This result implied that the presence of $\mathrm{Cu}$ and $\mathrm{Zn}$ cations promoted the sorption of PFOS on $\mathrm{AC}_{\mathrm{P} 05}$, which was consistent with the sorption experiment of PFOS (Fig. 5a). However, the thiol peak weakened from 2473.8 to $2472.9 \mathrm{eV}$ until it disappeared when the $\mathrm{Cu}$ and $\mathrm{Zn}$ cations were introduced into the sorption system. The cationic metals $\mathrm{Cu}$ and $\mathrm{Zn}$ can bond to the sulfur of PFOS and thiol to form a metal chelate compound, which resulted in the disappearance of the XANES signal attributed to the thiol. Because the metal chelate compound possessed a positive charge, it promoted the removal of the anionic PFOS and $\mathrm{HCrO}_{4}{ }^{-}$/ $\mathrm{Cr}_{2} \mathrm{O}_{7}{ }^{2-}$ via electrostatic attraction in the multivariate solutes system.

\section{Conclusions}

The activated carbon prepared by one-step microwave activation displayed multifunctional sorption performance for PFOS and Cr(VI). The analysis of the sulfur $\mathrm{K}$-edge X-ray absorption near edge structure indicated that $\mathrm{Cr}(\mathrm{VI})$ did not interfere with the sorption of PFOS on AC because the hydrophobic partition became the main driving force to support sorption instead of a mechanism involving electrostatic attraction. The coexistence of $\mathrm{Zn}$ and $\mathrm{Cu}$ cations promoted the removal of PFOS due to the formation of the metal chelate compound.

Acknowledgments This study was supported by the National Natural Science Foundation of China (Grant No. 41103076, 21207151) and the Youth Innovation Promotion Association (29QNCX2012005) of CAS. We thank the Beijing Synchrotron Radiation Facility (BSRF, China) for providing the beam time and Zheng Lei and Ma Chenyan for valuable assistance with the XANES experiments.

\section{References}

Ahrens, L., Gerwinski, W., Theobald, N., \& Ebinghaus, R. (2010). Sources of polyfluoroalkyl compounds in the North Sea, Baltic Sea and Norwegian Sea: evidence from their spatial distribution in surface water. Marine Pollution Bulletin, 60, 255-260.
Alslaibi, T. M., Abustan, I., Ahmad, M. A., \& Abu Foul, A. (2013). A review: production of activated carbon from agricultural byproducts via conventional and microwave heating. Journal of Chemical Technology and Biotechnology, 88, 1183-1190.

Boehm, H. P. (2002). Surface oxides on carbon and their analysis: a critical assessment. Carbon, 40, 145-149.

Brooke, D., Footitt, A., Nwaogu, T. A. (2004). Environmental risk evaluation report: perfluorooctane sulfonate (PFOS). Building Research Establishment Ltd., Risk and Policy Analysts Ltd., and UK Environment Agency's Science Group. (Available at URL: http://www.pops.int/documents/ meetings/poprc/prepdocs/annexFsubmissions/PFOS\% 20EC2.pdf). Accessed 29 Feb 2012.

Deng, H., Yang, L., Tao, G. H., \& Dai, J. L. (2009). Preparation and characterization of activated carbon from cotton stalk by microwave assisted chemical activation-application in methylene blue adsorption from aqueous solution. Journal of Hazardous Materials, 166, 1514-1521.

Deng, H., Zhang, G. L., Xu, X. L., Tao, G. H., \& Dai, J. L. (2010). Optimization of preparation of activated carbon from cotton stalk by microwave assisted phosphoric acid-chemical activation. Journal of Hazardous Materials, 182, 217-224.

Dicorcia, A., Marchese, S., \& Samperi, R. (1993). Evaluation of graphitized carbon-black as a selective adsorbent for extracting acidic organic-compounds from water. Journal of Chromatography A, 642, 163-174.

Foo, K. Y., \& Hameed, B. H. (2011). Preparation and characterization of activated carbon from sunflower seed oil residue via microwave assisted $\mathrm{K}_{2} \mathrm{CO}_{3}$ activation. Bioresource Technology, 102, 9794-9799.

Giesy, J. P., \& Kannan, K. (2001). Global distribution of perfluorooctane sulfonate in wildlife. Environmental Science and Technology, 35, 1339-1342.

Hashimoto, Y., \& Yamaguchi, N. (2013). Chemical speciation of cadmium and sulfur K-edge XANES spectroscopy in flooded paddy soils amended with zerovalent iron. Soil Science Society of America Journal, 77, 1189-1198.

Hesas, R. H., Daud, W. M. A. W., Sahu, J. N., \& Arami-Niya, A. (2013). The effects of a microwave heating method on the production of activated carbon from agricultural waste: a review. Journal of Analytical and Applied Pyrolysis, 100, $1-11$.

Huang, L. H., Sun, Y. Y., Wang, W. L., Yue, Q. Y., \& Yang, T. (2011). Comparative study on characterization of activated carbons prepared by microwave and conventional heating methods and application in removal of oxytetracycline (OTC). Chemical Engineering Journal, 171, 1446-1453.

Lam, N. H., Cho, C. R., Lee, J. S., Soh, H. Y., Lee, B. C., Lee, J. A., Tatarozako, N., Sasaki, K., Saito, N., Iwabuchi, K., Kannan, K., \& Cho, H. S. (2014). Perfluorinated alkyl substances in water, sediment, plankton and fish from Korean rivers and lakes: a nationwide survey. Science of the Total Environment, 491, 154-162.

Lin, A. Y. C., Panchangam, S. C., \& Lo, C. C. (2009). The impact of semiconductor, electronics and optoelectronic industries on downstream perfluorinated chemical contamination in Taiwanese rivers. Environmental Pollution, 157, 1365-1372.

Pan, G., \& You, C. (2010). Sediment-water distribution of perfluorooctane sulfonate (PFOS) in Yangtze River Estuary. Environmental Pollution, 158, 1363-1367. 
Shi, B. (1986). Analysis of existing forms of $\mathrm{Cr}^{6+}$ in waste water. Electroplating and Pollution Control, 6, 30-33.

Tang, C. Y. Y., Fu, Q. S., Robertson, A. P., Criddle, C. S., \& Leckie, J. O. (2006). Use of reverse osmosis membranes to remove perfluorooctane sulfonate (PFOS) from semiconductor wastewater. Environmental Science and Technology, 40, 7343-7349.

Vecitis, C. D., Park, H., Cheng, J., Mader, B. T., \& Hoffmann, M. R. (2009). Treatment technologies for aqueous perfluorooctanesulfonate (PFOS) and perfluorooctanoate (PFOA). Frontiers of Environmental Science and Engineering in China, 3, 129-151.

Wang, Y. T., \& Xiao, C. S. (1995). Factors affecting hexavalent chromium reduction in pure cultures of bacteria. Water Research, 29, 2467-2474.

Yu, Q., Zhang, R. Q., Deng, S. B., Huang, J., \& Yu, G. (2009). Sorption of perfluorooctane sulfonate and perfluorooctanoate on activated carbons and resin: kinetic and isotherm study. Water Research, 43, 1150-1158.

Yuan, P., Fan, M. D., Yang, D., He, H. P., Liu, D., Yuan, A. H., Zhua, J. X., \& Chen, T. H. (2009). Montmorillonite-supported magnetite nanoparticles for the removal of hexavalent chromium $[\mathrm{Cr}(\mathrm{VI})]$ from aqueous solutions. Journal of Hazardous Materials, 166, 821-829.

Zhang, Q. Y., Deng, S. B., Yu, G., \& Huang, J. (2011a). Removal of perfluorooctane sulfonate from aqueous solution by crosslinked chitosan beads: sorption kinetics and uptake mechanism. Bioresource Technology, 102, 2265-2271.

Zhang, T., Sun, H. W., Lin, Y., Wang, L., Zhang, X. Z., Liu, Y., Geng, X., Zhao, L. J., Li, F. S., \& Kannan, K. (2011b). Perfluorinated compounds in human blood, water, edible freshwater fish, and seafood in China: daily intake and regional differences in human exposures. Journal of Agricultural and Food Chemistry, 59, 11168-11176.

Zhou, Q., Deng, S. B., Yu, Q., Zhang, Q. Y., Yu, G., Huang, J., \& He, H. P. (2010). Sorption of perfluorooctane sulfonate on organo-montmorillonites. Chemosphere, 78, 688-694.

Zhou, Q., Pan, G., \& Shen, W. (2013a). Enhanced sorption of perfluorooctane sulfonate and $\mathrm{Cr}(\mathrm{VI})$ on organo montmorillonite: influence of solution $\mathrm{pH}$ and uptake mechanism. Adsorption, 19, 709-715.

Zhou, Q., Pan, G., \& Zhang, J. (2013b). Effective sorption of perfluorooctane sulfonate (PFOS) on hexadecyltrimethylammonium bromide immobilized mesoporous $\mathrm{SiO}_{2}$ hollow sphere. Chemosphere, 90, 2461-2466. 